\title{
Identifying the effect of a Basic life Support teaching Program on nurses' Knowledge and skills at Emergency care unit
}

\author{
Manal Mohammed Abd El Naeem, Nadia Taha Mohamed, Mona Aly Mohammed \& Mervet Anwar Abd El- \\ Aziz
}

Assistant Lecturer of Critical care Nursing, Faculty of Nursing, Assiut University, Egypt.

Professor of Critical Care \& Emergency Nursing Critical Care \& Emergency Nursing, Faculty of Nursing, Alexandria University, Egypt.

Assistant Professor, of Critical Care Nursing. Faculty of Nursing, Assiut University, egypt.

Assistant Professor, of Critical Care Nursing, Faculty of Nursing, Assiut University, Egypt.

\begin{abstract}
Nursing staff in the hospital are frequently the first to witness a cardiac arrest, they play a central role in the effective management of in-hospital cardiac arrest. Aim: Identifying the effect of a Basic life Support teaching Program on nurses' Knowledge and skills at Emergency care unit. Research design: A quasi experimental research design. Setting: Emergency care medical department at Assuit University Hospitals. Sample: Nurses working in selected setting and having more than one year clinical experience. Methods: Two tools were used for data collection. Knowledge and skills assessment tools. The current study was carried out on assessment of baseline nurses' level of knowledge and skills followed by implementation. The effect of teaching was carried out immediately after application of the program. Results: The study revealed that the majority of nurses had poor knowledge and skills related to CPR before teaching program which has been improved after teaching program. Conclusion, there was a significant improvement in the nurses' knowledge and skills related to CPR after teaching program. Recommendation annually assessment and refreshing courses to nursing staff with up- to- date guidelines to impart cognitive knowledge and psychomotor skills of CPR and to provide a standardized care to cardiac arrest patients.
\end{abstract}

Keywords: Cardiopulmonary Resuscitation (CPR), Basic life Support; Knowledge, Skill \& Teaching Program.

\section{Introduction}

Globally, one third of deaths each year are due to cardiovascular disease. Ischemic heart disease accounts for more than 17.3 million deaths annually, with $80 \%$ of these in low and middle-income countries.(WHO, 2013) Cardiovascular diseases (CVD), including ischemic heart disease, congestive heart failure, and stroke, account for more than a quarter of all deaths.(Sankar, Vijayakanthi \& Sankar, 2011)The World Health Organization (WHO) estimates there will be about 20 million CVD deaths in 2015. (IOM, 2010)

Undoubtedly, cardiac arrest(CA) is one of the most high risk situations which requires urgent, immediate and deliberate action to survive and protect life. These actions and measurements are implemented based on some specific protocols and its prerequisites are acquisition of the background knowledge, skill and experience by the resuscitator. Therefore, management, standardization and education of Cardiopulmonary resuscitation (CPR) process would be of high importance.(Salari et al., 2011)

Basic life support (BLS) may be defined as maintaining circulation, airway and breathing without any equipment except simple airways. It consists of four elements: initial assessment; chest compression; airway maintenance and expired air ventilation. It has been always known that CPR is not a single skill but a series of assessments and interventions. Nowadays, there are standards of basic life support agreed upon universally by several Committees and National Conferences. (Al Kandary et al., 2007)

In hospitals worldwide, the nurse plays a key role in the management of cardiac arrest as a witness at the forefront of the patient from the time when the acute event occurs until discharge. it is usually the nurse, who discovers a cardiac arrest . In addition, the nurse is an integral part of the resuscitation process, are requested many skills and knowledge that are implemented in a short time with efficiency and timeliness. For example, the Nurse evaluates the $\mathrm{ABC}$, deals with the evaluation of cardiac massage, artificial ventilation and administration of drugs. (Daniele, 2012). So, the Nurses need to know the skills and theories behind CPR as performing quality CPR might improve the patient's chance of survival and increase the opportunity of recovery. Thus, nurse's competency in CPR is a critical factor in determining successful patient outcomes from a 
cardiac arrest.(Sankar, Vijayakanthi \& Sankar 2011)

Despite the proven importance of CPR, survival rates remain low, mostly due to its ineffective administration. The quality of CPR is often poor in the clinical setting and the lack of resuscitation skills of nurses and doctors in BLS and advanced life support (ALS) has been identified as a contributing factor to poor outcomes of cardiac arrest victims. Improvement in CPR skills should therefore have considerable impact on mortality.(Sodhi, Singls \& Shrivastava 2011)

Poor knowledge and skill retention following cardiopulmonary resuscitation training for nursing and medical staff has been documented over the past 20 years (AL- Ghamdi, Essawy \& AL- Qahtani. 2014). CPR skills and knowledge deteriorate significantly if not used or regularly updated. (Pillai 2010) Numerous studies examined the resuscitation skills of nurses and nurses generally are poor at performing BLS and have a low overall level of ability. (Dwyer \& Mosel 2002)There is universal evidence to suggest that CPR knowledge is poorly recalled by nurses (N0ri et al., 2012 )

The development of knowledge and skills is an essential component of professional development in nurse education programs. Acquisition and retention of CPR knowledge and skills are vital in ensuring that nurses can respond quickly and effectively to patients in cardiopulmonary arrest. Education is a way of dealing with both the actual and perceived complexities of CPR. Furthermore, various international organizations on resuscitation have emphasized the importance of education on providing high quality CPR and thus improving survival from cardiac arrest (Bhanji et, al., 2010).

\section{Significance of the study}

As one can easily imagine the cardiac arrest is a matter of extreme importance, even from the standpoint of nursing. It is estimated that the morbidity rate in Egypt as result of cardiovascular diseases $(5.6 \%)$ and by 2015 over million people will suffer serious cardiac arrest. It has been documented that $33 \%$ to $40 \%$ of cardiac arrests in developed countries occur in the hospital setting, and of the arrests that occur in the hospital setting more than $60 \%$ are first recognized by nurses (Christel \& Woodward, 2000)

Several studies have demonstrated inadequate CPR skills in hospital nursing staff and even in welltrained nurses. Accordingly, problems in performing resuscitation might primarily be caused by insufficient training, inadequate methodological training approaches, or by a deterioration of CPR knowledge and skills over time (Taha 2012). Nagashima et al concluded that $80 \%$ of the nurses did not have enough knowledge about CPR.(Preusch et al., 2010) So, Aim of the study, Identifying the effect of a Basic life Support teaching program on nurses' knowledge and skills at emergency care unit.

Hypotheses

- There will be significant difference between posttest knowledge scores to the pretest knowledge scores following implementation of teaching program.

- There will be significant difference between post test skill scores to the pretest skill scores following implementation of teaching program.

- A positive relation will exist between knowledge and skill scores obtained by critical care nurses receiving teaching program.

\section{Subjects \& Methods}

\section{Research design}

A quasi experimental research design with one group pre-test post-test approach.

Setting: The study was conducted in emergency care medical department at Assuit University Hospitals.

Sample: Convenient sample of all nurses working in selected setting and having more than one year clinical experience (50 nurses) were included in the study.

Study tools: Two tools were used in this study:

Tool one (BLS knowledge assessment tool): This tool consisted of Structured multiple choice pre/posttest questionnaire tool. This tool was developed by researcher after reviewing literatures to assess the knowledge level of critical care nurses regarding BLS of CPR. This tool includes two parts:

Part I: Scio-demographic data of study sample which include: age, sex, educational level, marital status, years of experience, and previous training program.

Part II: Nurses' knowledge about anatomy and physiology of the heart, cardiac arrest and basic life support. It consist of forty five multiple choice questions covering five main parts:

- Basic knowledge about anatomy and physiology of the heart which included twelve questions.

- Basic knowledge about cardiac arrest which includes seven questions.

- Nursing care during CPR and its complications which includes twenty one questions.

- Nursing care for airway and ventilation using a bag-mask device which included five questions.

Scoring system for nurses' knowledge : A score value of 1 was awarded to each correct answer and zero was allotted for wrong answer. 
The total score of nurses' knowledge was calculated \& classified as follows: $75 \%$ and more was considered good, 74-60\% was considered fair, and less than $60 \%$ was considered poor.

Tool two (BLS skills assessment tool):This tool consists of observational Checklist. This tool was adopted from2010American Heart Association Guidelines for Cardiopulmonary Resuscitation for assessment of nurse's skills (Barbara, 2012 \& AHA. 2010). The tool covered all the steps procedure of nursing care for patients with cardiac arrest. The observational checklist comprised of 29 steps as follow:

- CPR procedure which includes ten steps.

- Upper airway suctioning which includes six steps.

- Oropharyngeal airway insertion which includes four steps.

- Bag-mask ventilation which includes five steps.

Scoring system for nurses' skills :The total score for all steps were 54 and every step was evaluated as follows; correctly done was scored (2), in-correctly done was scored (1) and not done was scored (0).

The total score of nurses' skills was calculated $\&$ classified as follows: $75 \%$ and more was considered good, 74-60\% was considered fair, and less than $60 \%$ was considered poor.

\section{Construction of the teaching program}

The teaching program was developed by the researcher based on the previous assessment of nurses' knowledge and skills, available resources and review of relevant literature

\section{General objective of the program}

The overall objective of the developed teaching program is to improve the critical care nurses 'knowledge and skills about (basic life support).

Specific objective of the program

By the end of the program nurses were able to:

Knowledge and understanding skills

- Recall of the anatomy of the heart.

- Recall of the physiology of the heart.

- Define cardiac arrest.

- List causes of cardiac arrest.

- Recognize sings that indicate cardiac arrest.

- Define cardiopulmonary resuscitation (basic life support).

- State purpose of cardiopulmonary resuscitation.

- List component of cardiopulmonary resuscitation.

- List the indications and contraindication for Oropharyngeal airway.

Intellectual skills

- Classify types of cardiac arrest

- Differentiate between cardiac arrest and cardiac attack.
- Summarize the 2010 adult BLS guidelines for healthcare providers

- Integrate the "Chain of Survival." For adults

- Organize fundamental aspects of BLS

- Prioritize elements of BLS

Professional skills

- Diagnose cardiac arrest

- Demonstrate the oral suctioning.

- Insert the Oropharyngeal airway

- Implement technique for Chest Compression

- Demonstrate technique of positive pressure ventilation using a bag-mask device

- Appraise complication of cardiopulmonary resuscitation.

General and transferable skills

- Communicate effectively with team work.

- Protect the manikin and equipment at the CPR unit.

Methods: The study was conducted on three phases (preparatory phase, implementation phase and evaluation phase).

Preparatory phase

- Permission to conduct the study was obtained from the hospital responsible authorities after explanation of the aim of the study.

- Tool one used in this study was developed in Arabic by the researcher based on reviewing the relevant literature.

- The tools were tested for content related validity by jury of five specialists in the field of critical care nursing and critical care medicine.

- The reliability was tested for tool one (knowledge assessment tool), tool two (skills assessment tool) by using Cronbach's coaefficient alpha $(\mathrm{r}=0.817$, 0.794 respectively) which is acceptable.

- A pilot study was conducted on five nurses to test the feasibility and applicability of the tool and the necessary modification was done.

- Permission for voluntary participation was obtained from nurses after the purpose of the study was explained.

- An approval was obtained from the local ethical committee and the study was followed the common ethical principles in clinical research.

- The researcher obtained was prepared through passing a workshop held by European Resuscitation Council in collaboration with the Egyptian Resuscitation Council a certificate approving that the researcher is capable for delivering and making BLS/AED procedure.

Development of the teaching program:

The teaching program was developed by the researcher, after reviewing the relevant literature . The following steps were adopted to develop the program: 
- Stating the program general and specific objectives.

- Planning the program: the content of the program were arranged into four teaching sessions in addition to preliminary one .

The content of the program covered two parts related to

- Knowledge about Cardiopulmonary resuscitation (basic life support) and its nursing management.

- Performance of procedures required for Cardiopulmonary resuscitation (basic life support).

Theoretical part included

- Anatomy and physiology of Cardiovascular system.

- Definition of Sudden cardiac arrest (SCA), classification, signs and symptoms, causes, and management of cardiac arrest.

- Definition of Cardiopulmonary resuscitation (CPR), benefits of CPR, the "Chain of Survival", component of Basic life support (BLS), the 2010 adult BLS guidelines for lay rescuers and healthcare providers, and complications of Cardiopulmonary resuscitation (basic life support).

Practical part included

- Upper airway suctioning procedure.

- Oral airway insertion procedure.

- Bag-mask ventilation procedure

- Chest compression.

Learning environment:

The program was conducted in head nurse's office at hospital and development center (CPR unit) at faculty of medicine.

Teaching methods

- Lectures and discussion by using audiovisual aids:

- PowerPoint presentation and booklet which developed in Arabic by the researcher based on reviewing was the related literature.

- Videos about Cardiopulmonary resuscitation basic life support (BLS) procedure, upper airway suctioning oral airway insertion, and bag-mask ventilation procedure adopted from CPR Training -ProCPR.org (2010 AHA Guidelines), Megacode from AHA, \& Code Blue Simulation. (www.ProCPR.org)

- Poster about basic life support included: technique for Chest Compression and technique of ventilation using a bag-mask device.

- Demonstration and re-demonstration using manikin the Ambu Man® CPR Manikin. (www.ambu-cpr-manikins.com)

- Scenarios for provides CPR practice. (www.aedchallenge.com)

Arranging the subgroup:
- The total sample was divided into ten subgroups included five nurses each session for better performance and understanding.

Implementation phase and evaluation phase:

- Assessment of knowledge was done twice as follows

- Once at beginning of study was considered as pretest assessment and as base line data for latter comparison with future post test.

- The second administration of questionnaire was carried out after implementation of the teaching program to identify its effect on nurses' knowledge.

- Assess nurses' skills

The researcher observes the nurses' skills using observational checklist tool twice before and immediately after teaching.

Evaluation of program

The evaluation of program was carried out by using post test.

Limitation of the study

Drop of some nurses from the study group .

Statistical analysis

- The data entry and data analysis were done using (SPSS Ver.19.).

- Descriptive statistics (number, percentage, mean and standard deviation) were done.

- Chi-square test was done to compare qualitative variables between before and after group .

- Pearson correlation between quantitative variables.

- P-value considered statistically significant when $\mathrm{p}<$ 0.05 . 


\section{Results}

Table (1): The Scio-demographic data of studied nurses.

\begin{tabular}{|c|c|c|}
\hline Scio-demographic data & No. $(n=50)$ & $\%$ \\
\hline \multicolumn{3}{|l|}{ Age } \\
\hline$<25$ years & 31 & 62.0 \\
\hline$\geq 25$ years & 19 & 38.0 \\
\hline Mean \pm SD (Range) & \multicolumn{2}{|c|}{$24.40 \pm 4.19(20.0-40.0)$} \\
\hline \multicolumn{3}{|l|}{ Gender } \\
\hline Female & 45 & 90.0 \\
\hline Male & 5 & 10.0 \\
\hline \multicolumn{3}{|l|}{ Level of education } \\
\hline 3 Years Nursing Diploma & 26 & 52.0 \\
\hline 5 Years Nursing Diploma & 5 & 10.0 \\
\hline Technical Health Institute & 12 & 24.0 \\
\hline Technical Institute of Nursing & 7 & 14.0 \\
\hline \multicolumn{3}{|l|}{ Experience } \\
\hline$<5$ years & 21 & 42.0 \\
\hline$\geq 5$ years & 29 & 58.0 \\
\hline Mean \pm SD (Range) & \multicolumn{2}{|c|}{$5.94 \pm 4.96(1.0-23.0)$} \\
\hline \multicolumn{3}{|l|}{ Training courses } \\
\hline Yes & 3 & 6.0 \\
\hline No & 47 & 94.0 \\
\hline
\end{tabular}

Table (2): The Total Score of Nurses' Knowledge categories before and after teaching program.

\begin{tabular}{|c|c|c|c|c|c|}
\hline \multirow[t]{2}{*}{ Total Score of Nurses' Knowledge categories } & \multicolumn{2}{|c|}{$\begin{array}{l}\text { Before } \\
(n=50)\end{array}$} & \multicolumn{2}{|c|}{$\begin{array}{c}\text { After } \\
(\mathbf{n}=\mathbf{5 0})\end{array}$} & \multirow[t]{2}{*}{ P-value } \\
\hline & No. & $\%$ & No. & $\%$ & \\
\hline \multicolumn{5}{|l|}{ Knowledge about anatomy and physiology of the heart } & \multirow{4}{*}{$0.000^{*}$} \\
\hline Poor & 42 & 84.0 & 8 & 16.0 & \\
\hline Fair & 2 & 4.0 & 6 & 12.0 & \\
\hline Good & 6 & 12.0 & 36 & 72.0 & \\
\hline \multicolumn{5}{|l|}{ Knowledge about cardiac arrest: } & \multirow{4}{*}{$0.000 *$} \\
\hline Poor & 35 & 70.0 & 7 & 14.0 & \\
\hline Fair & 8 & 16.0 & 10 & 20.0 & \\
\hline Good & 7 & 14.0 & 33 & 66.0 & \\
\hline \multicolumn{5}{|c|}{ Knowledge about nursing role during CPR and complications } & \multirow{4}{*}{$0.000 *$} \\
\hline Poor & 36 & 72.0 & 6 & 12.0 & \\
\hline Fair & 11 & 22.0 & 16 & 32.0 & \\
\hline Good & 3 & 6.0 & 28 & 56.0 & \\
\hline \multicolumn{5}{|c|}{ Knowledge about nursing role for oropharyngeal airway and ventilation } & \multirow{4}{*}{$0.000 *$} \\
\hline Poor & 32 & 64.0 & 2 & 4.0 & \\
\hline Fair & 11 & 22.0 & 3 & 6.0 & \\
\hline Good & 7 & 14.0 & 45 & 90.0 & \\
\hline \multicolumn{5}{|l|}{ Total knowledge } & \multirow{4}{*}{$0.000 *$} \\
\hline Poor & 40 & 80.0 & 4 & 8.0 & \\
\hline Fair & 9 & 18.0 & 13 & 26.0 & \\
\hline Good & 1 & 2.0 & 33 & 66.0 & \\
\hline
\end{tabular}

* Statistical significant difference $(P<0.05)$

Chi-square test 
Table (3): The Total Score of Nurses' Skills before and after teaching program.

\begin{tabular}{|c|c|c|c|c|c|}
\hline \multirow[t]{2}{*}{ Total Score of Nurses' Skills categories } & \multicolumn{2}{|c|}{$\begin{array}{l}\text { Before } \\
(n=50)\end{array}$} & \multicolumn{2}{|c|}{$\begin{array}{c}\text { After } \\
(\mathbf{n}=50)\end{array}$} & \multirow[t]{2}{*}{ P-value } \\
\hline & No. & $\%$ & No. & $\%$ & \\
\hline \multicolumn{5}{|l|}{ Skills of CPR } & \multirow{4}{*}{$0.000^{*}$} \\
\hline Poor & 47 & 94.0 & 3 & 6.0 & \\
\hline Fair & 2 & 4.0 & 2 & 4.0 & \\
\hline Good & 1 & 2.0 & 45 & 90.0 & \\
\hline \multicolumn{5}{|l|}{ Skills of upper airway suctioning } & \multirow{4}{*}{$0.000 *$} \\
\hline Poor & 34 & 68.0 & 1 & 2.0 & \\
\hline Fair & 4 & 8.0 & 8 & 16.0 & \\
\hline Good & 12 & 24.0 & 41 & 82.0 & \\
\hline \multicolumn{5}{|l|}{ Skills for oral airway insertion } & \multirow{4}{*}{$0.000 *$} \\
\hline Poor & 48 & 96.0 & 15 & 30.0 & \\
\hline Fair & 0 & 0.0 & 0 & 0.0 & \\
\hline Good & 2 & 4.0 & 35 & 70.0 & \\
\hline \multicolumn{5}{|l|}{ Skills for bag-mask ventilation } & \multirow{4}{*}{$0.000 *$} \\
\hline Poor & 29 & 58.0 & 11 & 22.0 & \\
\hline Fair & 17 & 34.0 & 4 & 8.0 & \\
\hline Good & 4 & 8.0 & 35 & 70.0 & \\
\hline \multicolumn{5}{|l|}{ Total skills } & \multirow{4}{*}{$0.000 *$} \\
\hline Poor & 47 & 94.0 & 1 & 2.0 & \\
\hline Fair & 0 & 0.0 & 10 & 20.0 & \\
\hline Good & 3 & 6.0 & 39 & 78.0 & \\
\hline
\end{tabular}

* Statistical significant difference $(P<0.05)$

Chi-square test

Table (4): The correlation between total score of nurses' knowledge with skills categories before and after teaching program.

\begin{tabular}{|c|l|c|c|}
\hline \multirow{2}{*}{ Skills } & & \multicolumn{2}{|c|}{ Total knowledge } \\
\cline { 3 - 4 } & & Before & After \\
\hline \multirow{2}{*}{ Skills of CRR } & r-value & 0.155 & $\mathbf{0 . 5 6 4}$ \\
\cline { 2 - 4 } & P-value & 0.281 & $\mathbf{0 . 0 0 0}$ \\
\hline \multirow{2}{*}{ Skills of upper airway suctioning } & r-value & 0.260 & -0.098 \\
\cline { 2 - 4 } & P-value & 0.068 & 0.500 \\
\hline \multirow{2}{*}{ Skills for oral airway insertion } & r-value & 0.077 & 0.020 \\
\cline { 2 - 4 } & P-value & 0.597 & 0.892 \\
\hline \multirow{2}{*}{ Skills for bag-mask ventilation } & r-value & 0.171 & 0.166 \\
\cline { 2 - 4 } & P-value & 0.234 & 0.249 \\
\hline \multirow{2}{*}{ Total skills } & r-value & 0.240 & $\mathbf{0 . 3 2 3}$ \\
\cline { 2 - 4 } & P-value & 0.093 & $\mathbf{0 . 0 2 2} *$ \\
\hline
\end{tabular}

* Statistical significant difference $(P<0.05)$

Pearson test

\section{Section I: The socio-demographic of studied} nurses

Table (1): Shows the Scio-demographic data of studied nurses. It was found that $62 \%$ of them were in the age group less than 25 years, and $90 \%$ were female. Concerning their educational level, $52 \%$ of the nurses held 3 Years Nursing Diploma,. Moreover, $58 \%$ nurses had work experience more than 5 years . In relation to their previous training on CPR, the table reveals that, $94 \%$ of them were not receiving any previous CPR training.

Section II: Testing of research hypotheses I

There will be significant difference between posttest knowledge scores to the pretest knowledge scores following implementation of teaching program.

Table (2): Presents that the total score of nurses' knowledge categories before and after teaching program. It was observed that there were statistical 
significant differences between nurses' knowledge categories indicating good knowledge after teaching program, compared with poor knowledge before teaching program.

Section III: The testing of research hypotheses II There will be significant difference between post test skill scores to the pretest skill scores following implementation of teaching program

Table (3) Present that the total score of nurses' skills before and after teaching program. It was observed that there were statistical significant differences between nurses' skills categories indicating good skills after teaching program, compared with poor skills before teaching program

Section IV: The testing of research hypotheses III A positive relation will exist between knowledge and skills score obtained by critical care nurses receiving teaching program Table (4): Presents the correlation between total score of nurses' knowledge with skills before and after teaching program. There was no correlation between total score knowledge and skills of nurses before teaching program. while, a significant positive correlation was found between total score of nurses' knowledge related to skills of CRR and total skills after teaching program ( $r$ value $=0.564$ and 0.323 ) respectively.

\section{Discussion}

Cardiopulmonary resuscitation (CPR) has been identified as a core emergency skill in which all health care professionals should be proficient. Nurses, by the very nature of their work, are often the first to initiate CPR when an emergency occurs. As the role of the nurse continues to expand, the boundaries between what is considered to be nursing interventions and what is considered to be medical interventions will become more blurred. With an expanded role come more responsibilities that require nurses to have a high standard of knowledge and skills, specifically in CPR. However, research and related literature has shown that nurses have varying levels of competence in CPR and that CPR skills deteriorate over time. (Kipsang \& Bruce 2011) So, The present study aim to evaluate effect of implementing Cardiopulmonary resuscitation teaching program on knowledge and skills of critical care nurses

The current study figured out that, the level of knowledge of the majority of studied nurses generally was poor. This might be related to the fact that majority of them hold nursing diploma and most of books are written in English and their learning in Arabic. This causes problems for them to learn. Another cause for lack of knowledge is that most of them were not receiving any previous training about
CPR. The technical nurses in the current study have lack of knowledge about the updating CPR guidelines and earlier undergraduates received courses that put more emphasis on pre-hospital CPR rather than on inhospital CPR.

This lack of knowledge may be also due to absence of pre-employment orientation programs, in-service CPR training and courses. Moreover, the nurses in Egypt not used the independent self-learning. Another cause for lack of many of knowledge nurses' exhaustion due to increased work load which may hinder their ability to read and update their knowledge.

The present study finding was Supported by (Hamed 2009) who studied "Nurse's performance during cardiopulmonary resuscitation in intensive care unit and cardiac care unit at Benha University Hospital", the present study found that the majority of nurses in both units have secondary diploma degree and the result of study also indicated that most of nurses had not trained and found that the majority of the study nurses had unsatisfactory knowledge about CPR. Also, (Parajulee \& Selvaraj 2011) stated that more than third of the nurses didn't have any previous information regarding CPR, and mostly all of them were willing to attend training program and reported that they have the capacity to perform CPR and they found low percentage of knowledge among the respondents.

This result was similar to the result revealed by (AlJanabi \& Al-Ani 2014) they concluded that most of the sample $(61.2 \%)$ did not have any formal training courses on cardio-pulmonary resuscitation and the majority of the nurses had poor knowledge concerning cardiac arrest and cardiopulmonary resuscitation. On the same line (Xiu-zhen et al., 2008) revealed that knowledge of $C P R$ among the community nurses based health services in Hainan province at China was poor in general, especially those who are from rural and town background. They also have lower academic qualifications with lower passing rate. (Rajeswaran \& Ehlers 2014) reported that $52.0 \%$ of the respondents had no formal CPR training and $70.0 \%$ had received no CPR training after completion of their basic training. And the pretest mean score achieved by participants in the tests that assessed their average CPR knowledge was $55.09 \%$.

Whereas, (Nagashima et al. 2012) was in contrast with the present study results and stated that the majority of the nurses are much interested in CPR, and most of them had received education and training in CPR as students or after the graduation.

For significant improvement in nursing staff knowledge after the application of the teaching program about CPR. This improvement might be 
related to the fact that providing teaching materials as booklet and posters about the latest CPR guidelines, and focusing on in-hospital CPR. In addition, using group discussion teaching method for encourage with continuous feedback to ensure understanding and achievement of the specific objectives of the program.

This result is in accordance with a study conducted by (Sankar et al., 2011) who studied Effect of a Training Module in Cardiopulmonary Resuscitation on the Knowledge and Skills of Pediatric Nursing Personnel. He documented that, knowledge and skills of pediatric nursing personal posted in acute areas improved with the new teaching program. Also, (Alshonee et al., 2014) figured out that, there was a significant improvement in nursing staff knowledge after the application of the training program about CPR.

In addition, (Hirose et al., 2014) reported that a simplified 45min CPR training program combining instruction and practice in chest compression and AED use improved the quality of CPR and the attitude towards CPR and AED use of the nonmedical staff working at a university hospital. (Elazazay et al., 2012) proved that nurse's knowledge scores were poor in all knowledge items pre the training program which has been strongly increased post the program.

Regarding the nurse's knowledge about the oral suctioning, The current study showed that the level of nurse's knowledge was poor pre-program, while after program implementation, an improvement were recorded with significant statistical difference. These findings are supported by (Taha 2004) who reported that knowledge of participating nurses regarding oral and naso-pharyngeal suctioning, was high with a significant statistical difference between pre-and immediate post program.

The current study represent that level of performance of half of studied nursing regarding check for response and breathing of patient was performed correctly. This may be related to nurse's level of knowledge in relation to check for response and breathing of patient was good and easy to performance. These findings are supported by (Mohamed 2014) reported that the majority of studied nurses with assessment of patient's responsiveness and breathing were high.

Finding of current study represent that the level of performance of more than half of studied nursing with activate emergency response system or shout for help was performed incorrectly. These findings may be related to unavailability of the emergency response system in hospital and the nurse leave the patient and go to the physician to tell him that the patient was arrested. These findings are supported by
(Whetzel et al., 2013) concluded that many emergency nurses have not taken basic actions to prepare themselves for a disaster, either personally or professionally.

On the contrary, (Elazazay et al., 2012) documented that the ability to respond quickly and effectively to a cardiac arrest situation rests on nurse being competent in the emergency life-saving procedure of CPR.

Finding of the current study revealed that level of performance of chest compression was performed incorrectly for most of the studied nurses. This may be due to many factors, including inadequate information about right site of compression and international guidelines, nurse's fatigue and inadequate supervision by the nursing supervisors. (Taha 2006) reported that more than half of nurses had unsatisfactory practice level about CPR. Also, (Sánchez et al., 2015) documented that compliance with the 2010 guidelines' quality criteria of CPR is often poor between Seventy-two nurses and physicians trained in advanced cardiopulmonary resuscitation performed.

Finding of the current study shows that the level of performance of the majority of studied nurses providing rescue breathing was performed incorrectly. This could be attributing to the fact that the finding of present study indicated insufficient training regarding technique of bag-mask ventilation and low level of knowledge for the majority of the studied nurses in relation to providing rescue breathing, and that providing rescue breathing is complex procedure. This insufficient knowledge and training may be related to that minimal educational emphasis on the in-hospital CPR technique in the nursing schools, absence of pre-employment orientation, and in-service training programs.

These result is in accordance with a study conducted by (Nicol et al., 2011) who indicated that the proportion of the interns who can correctly providing initial rescue breathing and ventilation technique was lower than the other measured skills. Moreover, (Manomayangkul., 2013) found that only 3.5\% of the nurses were mostly compliant with providing rescue breathing. In addition, (Mohamed 2014) reported that the level of compliance of majority of the studied nurses with providing rescue breathing was low.

The present study proved that nurses' performance was poor in all performance items before the teaching program which has been changed to good immediately after teaching program. This improvement might be related to the fact that majority of them are young, not receiving any previous training about $\mathrm{CPR}$ and have $\geq 5$ year of experience, but the nurses were enthusiastic to learn. 
In addition to, the highly expressed need of this group of nurses to learn more about certain areas like managing patient airways, and technique of correct resuscitation. Finally this improvement might be related to use new video-based instruction, scenarios and demonstration using simulators. This result was agreed with (Nielsen et al., 2010) reported that Untrained lay persons attending a 24 min DVD-based BLS course have a significantly improved BLS performance after 31/2-4 months compared to pre-test skill performance. (Govender et al., 2010) the study showed that the new video-based instruction for skills development and practice is able to provide highquality training in BLS and that skills retention is similar to that in other methods of teaching.

On the same line, (Hirose et al., 2014) conducted that a questionnaire survey to evaluate participants' attitudes towards CPR and AED use and demonstrated an improvement in their attitudes after the training. Also, (Elazazay et al., 2012) stated that nurses performance was very poor in all performance items pre the program which has been strongly increased immediately post the program. Also, this was supported by (AL-Ghamdi et al., 2014) who studied effect of frequent application of Code Blue training program on the performance of pediatric Nurses. Documented that, the mean of the nurses' performance was poor before the program implementation as seen in the first session of training compared to the improvement that have been noticed after the third training session.

As regarding, the relationship between knowledge and skills. there will be a positive correlation between nurse's knowledge and skills scores. This reflects the importance of integration between theory and practice. In the same line, (Taha 2006) illustrated that nurses should attain and maintain a high level of nursing knowledge and nursing practice but to be effective in practice, nurses must gain knowledge before they enter practice.

These result are in line with the result reported by (Elazazay et al., 2012) and (Alshonee et al., 2014) who found that a positive significant correlation between nurses knowledge and performance related to CPR pre and one month post the training program, and (Aly 2010) reported that there was significant correlation between total knowledge and practice scores. These findings contradicted (Mahrous 2003) reported that there is no correlation between knowledge and practice of diploma nurses.

\section{Conclusions}

Based on the results of this study, it can be concluded that:
- A statistical significant improvement of knowledge immediately after application of teaching program regarding CPR.

- A statistical significant improvement of skills immediately after application of teaching program regarding CPR.

- There is correlation found between knowledge and skills scores obtained by critical care nurses receiving teaching program.

\section{Recommendations}

Based on the finding of the current study, the following recommendations are suggested:

Recommendation regarding administration:

- The latest guidelines of CPR should be available in written format in critical care units and emergency units.

- Hospital wards need to be equipped with better facilities for CPR and with readily accessible e.g AED.

- Establishment of Crash team (Code team) designated staff member who have particular expertise in resuscitation, who are called to the scene of all arrests within hospital.

Recommendations Regarding Education and Training

- Integrate the necessary knowledge and skills related to the risk factors, etiology and prevention measures of cardiac arrest in in-service training to help the nurses in recognition of the patient at risk for cardiac arrest.

- Included in-hospital CPR teaching program in the nursing schools and undergraduates' curriculum.

- Pre-employment orientation, in-service education and training programs regarding CPR should be for all .

- Learning facilities such as update resources available to promote self learning regarding CPR.

Recommendation regarding nursing practice:

- Regular resuscitation training for all nurses.

- All nurses should be familiar with most piece of technology and equipment that is stored on the emergency trolley .

- The use of educational resources such as simulator manikins which allows participants to experience an emergent critical situation, take action, and review consequences of choices without jeopardizing patient safety.

Recommendation regarding the research:

- Repeat this research on large sample size and in different settings for generalization.

- Monitor the effectiveness of CPR technique on the survival rate. 


\section{References}

1. Al Kandary S., al Jeheidli A., Ghayath T., Al Haid N., (2007): Perceived Competence in cardiopulmonary resuscitation, knowledge and practice among qualified nurses in Kuwait. Bull Alex. Fac.Med. 43 No.2

2. AL-Ghamdi G., Essawy M., \& Al-Qahtani M., (2014): Effect of Frequent Application of Code Blue Training Program on the Performance of Pediatric Nurses Journal of American Science;10(5)

3. Al-Janabi M., Al-Ani B., (2014): Assessment of Nurses' Knowledge towards Cardiopulmonary Resuscitation at Al-Najaf City's Teaching Hospital. Journal of Kufa for Nursing Science Vol. (4) No.(1)

4. Alshonee S., Elsayed E., Elsharkawy H., \& Mohamed A., (2014): Effect of educational training about cardiopulmonary resuscitation on pediatric nurses' practice International Journal of Current ResearchVol. 6, Issue, 09, p.8781-8788,

5. Aly A., (2010): Impact of a Basic life Support Training Program on nurses' Knowledge and Performance at Emergency Room. Doctorate thesis. Faculty of Nursing. Port Saied University.

6. Bhanji F., Mancini M., Sinz E., Rodgers D., McNeil M., Hoadley T., Meeks R., Hamilton M., Meaney P., Hunt E., Nadkarni V., Hazinski M., (2010): Part 16: education, implementation, and teams: 2010 American Heart Association Guidelines for Cardiopulmonary Resuscitation and Emergency Cardiovascular Care. Circulation.;122(suppl 3):S920 -S933.

7. AHA BLS for health providers course1- and 2- Rescuer Adult BLS with AED Skills Test Sheet. (2010): Available at : American Heart Association: http://guidelines.ecc.org/guidelines-for-cpr.html

8. Christel A., Woodward, (2000): Strategies for assisting health workers to modify and improve skills: Developing quality health care - a process of change Evidence and Information for Policy Department of Organization of Health Services Delivery World Health Organization Geneva. 25-26

9. Daniele M., (2012): The Nursing Management of Cardiac Arrest in the Emergency Departments: The Experience of Cuneo. 1: 138. doi:10.4172/ scientificreports.138

10. Dwyer T., Mosel L., (2002): Nurses' behavior regarding CPR and the theories of reasoned action and planned behavior. Resuscitation 52, 85-90.
11. Elazazay H., Abdelazez A., \& Elsaie O., (2012): Effect of Cardiopulmonary Resuscitation Training Program on Nurses Knowledge and Practice Life Science Journal;9(4)

12. Govender K., Rangiah C., Ross A., Campbell L., (2010) :Retention of knowledge of and skills in cardiopulmonary resuscitation among healthcare providers after training .SA Fam Pract;52(5):459-462

13. Hamed, S., (2009): Nurses performance during cardio-pulmonary resuscitation in Intensive Care Unit and Cardiac Care Unit at benha University hospital,Master thesis, Faculty of Nursing,Benha University.

14. Hirose T., Iwami T., Ogura H., Matsumoto H., Sakai T., Yamamoto K., Mano T., Fujino Y., \& Shimazu T., (2014) :Effectiveness of a simplified cardiopulmonary resuscitation training program for the non-medicalstaff of a university hospital Journal of Trauma, Resuscitation and Emergency Medicine, 22:31

15. IOM (Institute of Medicine).(2010): Promoting Cardiovascular Health in the Developing World: A Critical Challenge to Achieve Global Health. Washington, DC: The National Academies Press. P 49.

16. Kipsang J., \& Bruce J., (2011): A comparison of cardiopulmonary resuscitation competence between two groups of advanced practice student nurses at Medical Training College in Kenya.Africa Journal of Nursing and Midwifery $13(2)$

17. Mahrous, F., (2003): Standards of nursing care for cardiac arrhythmic patients, Master thesis, Faculty ofNursing, Ain Shams University; P. 34.

18. Manomayangkul K., Siriussawakul A., Wangtawesap K., Chaiwat O., Chakorn T., Parakkamodom S., Saengsung P., Chawaruechai T., Komoltri C., (2013)Ward Characteristics Related to Quality and Pitfalls of Basic Life Support in Cardiopulmonary Resuscitation Simulated Survey. Siriraj Med $\mathrm{J} ; 65: 41-46$

19. Mohamed H., (2014): nurses' Compliance with Cardiopulmonary Resuscitation Guidelines in the emergency and critical care units. Master thesis, Faculty of Nursing, Alexandria University.

20. Nagashima K., Takahata O., Fujimoto A., \& Iwasaki H., (2012): Investigation of nurses' knowledge and experience in cardiopulmonary resuscitation. Resuscitation,;14(2):104-107.

21. Nicol P., Carr S., Cleary G., \& Celenza A., (2011): Retention into internship of resuscitation skills learned in a medical student resuscitation program incorporating an Immediate Life Support course. Resuscitation. Jan;82(1):45-50. 
22. Nielsen A., Henriksen M., Isbye D., Lippert F., Rasmussen L., (2010): Acquisition and retention of basic life support skills in an untrained population using a personal resuscitation manikin and video self-instruction. Resuscitation, Volume 81, Issue 9, Pages 11561160

23. Nori J., Saghafinia M., Motamedi M., Hosseini S., (2012): CPR Training for Nurses: How often Is It Necessary?. Iran Red Crescent Med J; 14(2):104-107.

24. Parajulee S., Selvaraj V., (2011): Knowledge of Nurses towards Cardiopulmonary Resuscitation in a Tertiary Care Teaching Hospital in Nepal. Journal of Clinical and Diagnostic Research; 5(8): 1585-1588.

25. Pillai J., (2010): Effectiveness of American Heart Association (AHA) Certified Basic Life Support (BLS) Training Among the Nurses Working in Selected Hospitals of Pune City. Proposal for Ph D Faculty of Health Sciences

26. Preusch M., Beaa F., Roggenbach J., Katusa H., Jünger J., \& Nikendei C., (2010): Resuscitation Guidelines 2005: does experienced nursing staff need training and how effective is it?American Journal of Emergency Medicine 28, 477-484

27. Rajeswaran L\&Ehlers V., (2014): Cardiopulmonary resuscitation knowledge and skills of registered nurses in Botswana, Curationis 37(1).

28. Salari A., Mohammadnejad E., Vanaki Z., \& Ahmadi F., (2011): Effect of in-hospital Cardiopulmonary Cerebral Resuscitation Management on Resuscitation Outcomes Iranian Journal of Critical Care Nursing, Volume 4, Issue 1; 13 - 22.

29. Sánchez B., Algarte R., Piacentini E., Trenado J., Romay E., Cerdà M., Ferrer R., \& Quintana S., (2015): Low compliance with the 2 minutes of uninterrupted chest compressions recommended in the 2010 International Resuscitation Guidelines.Journal of Critical Care, In Press, Corrected Proof, Available online 7 March

30. Sankar J., Vijayakanthi N., \& Sankar J., :(2011) Effect of a Training Module in Cardiopulmonary Resuscitation on the Knowledge and Skills of Pediatric Nursing Personnel. Indian Journal of Emergency Pediatrics 3(3)

31. Sodhi K., Singla M., \& Shrivastava A., (2011): Impact of advanced cardiac life support training program on the outcome of cardiopulmonary resuscitation in a tertiary care hospital Indian J Crit Care Med. Oct-Dec; 15(4): 209-212.

32. Taha A., (2012) :Impact of Adesigned Teaching Protocol about Advanced Cardiac Life Support (ACLS) On Critical CareNurse's Knowledge and Practices at Benha University Hospital, Cairo, Egypt. Journal of American Science 2012;8(10)

33. Taha, A., (2006): Emergency nursing care for critically ill patients: Impact of a designed teaching protocol on nurses knowledge and practices at Intensive Care Units (ICUS) of Benha University and Benha Teaching Hospitals, Master thesis, Faculty ofNursing, Benha University.

34. Taha, N., (2004): Comatosed patients: Impact of a training program provided for nurses working critical care units, Zagazig University Hospitals on Nurses' knowledge and performance levels as well on patient's outcome, Doctorate thesis, Faculty of Nursing, Zagazig University.

35. The World Health Organization. Media centre cardiovascular diseases (2013): Available at: www.who.int/mediacentre/factsheets/fs317/en/

36. Whetzel E., Walker-Cillo G., Chan K., \& Trivett J., (2013): Emergency Nurse Perceptions of Individual and Facility Emergency Preparedness.Journal of Emergency Nursing, Volume 39, Issue 1, January, Pages 4652

37. Xiu zhen C., Rui lian Z., Yan mei F., \& Tao W., (2008): Survey of the knowledge of cardiopulmonary resuscitation in the nurses of community-based health services in the Hainan province. Al Ameen J Med Sci;1:93 -8

38. www.ambu-cpr-manikins.com

39. www.aedchallenge.com 